\title{
ANTONIO BANDEIRA TRAJANO E A RENOVAÇÃO PEDAGÓGICA LIDA EM LIVROS ESCOLARES: ENSINAR ARITMÉTICA DE MODO INTUITIVO (FINAL DO SÉCULO XIX)
}

\author{
Marcus Aldenisson Oliveira ${ }^{1}$
}

\section{RESUMO}

Este artigo apresenta resultados de pesquisas que foram sendo desenvolvidas desde a iniciação científica ao doutorado. Ao trafegar por tantos caminhos possíveis de pesquisas, sempre me sentir atraído pelo tema o ensino intuitivo de Aritmética em escolas primárias, durante o final do século XIX. Ao tomar para análise a trilogia aritmética de Antonio Bandeira Trajano - Aritmética Primária, Aritmética elementar ilustrada e Aritmética progressiva -, cheguei à uma clara evidência de que o Brasil apropriou dos Estados Unidos não só um modelo pedagógico - o ensino intuitivo de Aritmética -, mas também um modelo gráfico-editorial de livro escolar. Para além disso, as três obras aqui analisadas são testemunhas das primeiras tentativas de constituição de uma pedagogia da Aritmética em escolas primárias brasileiras, a qual denominei de pedagogia prático-intuitiva.

Palavras-chave: Antonio Bandeira Trajano, aritmética, livro escolar, método intuitivo, pedagogia prático-intuitiva.

\footnotetext{
${ }^{1}$ Universidade Estadual Paulista "Júlio de Mesquita Filho" (Unesp), Araraquara/SP, Brasil.
} 


\title{
ANTONIO BANDERA TRAJANO Y LA RENOVACIÓN PEDAGÓGICA LIDA EN LIBROS ESCOLARES: ENSEÑAR ARITMÉTICA DE MODO INTUITIVO (FINALES DEL SIGLO XIX)
}

\section{RESUMEN}

Este artículo presenta resultados de investigaciones que fueron desarrolladas desde la iniciación científica al doctorado. Al traer por tantos caminos posibles de investigaciones, siempre sentirme atraído por el tema la enseñanza intuitiva de Aritmética en escuelas primarias, durante el final del siglo XIX. Al tomar para análisis la trilogía aritmética de Antonio Bandeira Trajano - Aritmética Primária, Aritmética elementar ilustrada e Aritmética progressiva -, llegué a una clara evidencia de que Brasil apropió de Estados Unidos no sólo un modelo pedagógico - la enseñanza intuitiva de Aritmética -, pero también un modelo gráfico-editorial de libro escolar. Además, las tres obras aquí analizadas son testigos de los primeros intentos de constitución de una pedagogía de la Aritmética en escuelas primarias brasileñas, la cual denominé de pedagogía prácticointuitiva.

Palabras clave: Antonio Bandeira Trajano, aritmética, libro escolar, método intuitivo, pedagogía práctico-intuitiva.

\section{ANTONIO BANDEIRA TRAJANO AND THE PEDAGOGICAL RENEWAL READ IN SCHOOLBOOKS: TEACH ARITHMETIC INTUITIVELY (LATE NINETEENTH CENTURY)}

\begin{abstract}
This article presents results of researches that were developed from the scientific initiation to the doctorate. While traveling through so many possible paths of research, I always feel drawn to the topic of intuitive teaching of Arithmetic in primary schools during the late nineteenth century. Taking the arithmetic trilogy of Antonio Bandeira Trajano - Aritmética Primária, Aritmética elementar ilustrada e Aritmética progressiva -, for analysis, I came to clear evidence that Brazil appropriated not only a pedagogical model of the United States - the intuitive teaching of Arithmetic -, but also a graphic-editorial model of a school book. In addition, the three works analyzed here are witnesses of the first attempts to constitute an Arithmetic pedagogy in Brazilian primary schools, which I have called practical-intuitive pedagogy.
\end{abstract}

Keywords: Antonio Bandeira Trajano, arithmetic, schoolbook, intuitive method, practicalintuitive pedagogy. 


\section{ANTONIO BANDEIRA TRAJANO ET LA RENOUVEAU PÉDAGOGIQUE LU DANS LES MANUELS SCOLAIRES: ENSEIGNER ARITHMÉTIQUE DE MANIÈRE INTUITIF (FIN DU XIXE SIECLE)}

\section{RÉSUMÉ}

Cet article présente les résultats de recherches qui ont été développées à partir de l'initiation scientifique au doctorat. En parcourant tant de chemins de recherche possibles, je me sens toujours attiré par le thème de l'enseignement intuitif de l'arithmétique dans les écoles primaires à la fin du XIXe siècle. Prenant la trilogie arithmétique d'Antonio Bandeira Trajano - Aritmética Primária, Aritmética elementar ilustrada e Aritmética progressiva -, pour l'analyse, je suis venu à l'évidence que le Brésil s'appropriait non seulement un modèle pédagogique des États-Unis l'enseignement intuitif de l'arithmétique -, mais aussi un modèle graphique-éditorial d'un livre d'école. De plus, les trois œuvres analysées ici sont les témoins des premières tentatives de constituer une pédagogie arithmétique dans les écoles primaires brésiliennes, ce que j'ai appelé la pédagogie pratique-intuitive.

Mots-clés: Antonio Bandeira Trajano, arithmétique, manuel scolaire, méthode intuitive, pédagogie pratique-intuitive. 


\section{INTRODUÇÃO}

Este artigo tem por tema o ensino intuitivo de Aritmética em escolas primárias, durante o final do século XIX. O objeto de pesquisa aqui construído teoricamente é a Aritmética da escola primária. Tal construção teórica tem sido possível a partir do cruzamento de resultados de várias pesquisas. Segundo Valdemarin (2010, p. 50), "o processo de construção de um objeto de pesquisa é dado por desvio e não por atalho". Nesse sentido, fica claro que por trás da exposição de resultados pesquisas estão presentes movimentos cognitivos/teóricos do pesquisador frente ao objeto em construção. Isso porque, de acordo com Valdemarin (2010, p. 48), cada "avanço [de pesquisa] implica retornos e revisões”. Nessa dinâmica cíclica de retornos e revisões se tira a lição: “A pesquisa científica é atividade medida pelo tempo" (VALDEMARIN, 2010, p. 47). E os resultados aqui apresentados são frutos dessa dinâmica cíclica marcada pela não linearidade da atividade científica, que tem sido caracterizada e medida pelo tempo.

Tudo começou lá em 2009, quando a professora doutora Ester Fraga Vilas-Bôas Carvalho do Nascimento, selecionou-me para ser seu bolsista de iniciação científica. Naquela ocasião, tive a oportunidade de desenvolver o projeto intitulado Circulação dos padrões norte-americano e francês na Matemática durante o Brasil oitocentista, de 2009 a 2010. Tratava-se de um estudo comparativo de dois livros didáticos de Matemática que circularam em escolas públicas e privadas brasileiras a partir do ano de 1883. O que se buscava era analisar os padrões educacionais presentes na elaboração da obra Aritmética elementar ilustrada, com autoria de Antonio Bandeira Trajano, e na obra Método para aprender a contar com segurança e facilidade, de Marie Jean Antoine Nicolas Caritat, o marquês de Condorcet, que contemplara respectivamente o método de ensino intuitivo e o método de ensino denominado de tradicional. Foi a partir desse projeto que tive o primeiro contato com a produção de livros escolares de Antonio Bandeira Trajano. 
Ainda na iniciação científica, desenvolvi também sob a orientação da Profa. Ester Nascimento outro estudo fora do campo da História da Educação Matemática, porém ligado à História da Educação. Refiro-me à pesquisa intitulada Livros e Leitores: A Biblioteca de Vicente Themudo Lessa, desenvolvida entre 2010 e 2011. Essa investigação tinha como objetivo analisar os 644 títulos catalogados por Vicente Themudo Lessa, os quais compuseram a sua biblioteca particular e que atualmente fazem parte do acervo inicial do Arquivo da Igreja Presbiteriana Independente, em São Paulo.

Essa mudança de campo de investigação não diminuiu minha curiosidade pela História da Educação Matemática. Pelo contrário. Esses dois projetos desenvolvidos na iniciação científica foram fundamentais para a minha formação como pesquisador. Mais que isso. O desenvolvimento desses projetos me auxílio a não só aprender a trabalhar com diferentes documentos (fontes) e ferramentais teórico-metodológicos, mas também na melhor delimitação do campo de investigação que eu teria, e tenho, interesse de pesquisa. A entrada no mestrado, para o desenvolvimento do projeto Antonio Bandeira Trajano e o método intuitivo para o ensino de Arithmetica (1879-1954)2, sob a orientação da Profa. Dra. Ilka Miglio de Mesquita, mostra que o meu interesse de pesquisa passou a ser o campo da História da Educação Matemática. O desenvolvimento da pesquisa A Aritmética escolar e o método intuitivo: Um novo saber para o curso primário (1870-1920)3, sob a orientação do Prof. Dr. Wagner Rodrigues Valente, no doutoramento, evidencia isso que estou falando sobre o meu interesse de investigação nesse campo.

De acordo com Valdemarin (2010, p. 47), nas atividades de pesquisa desenvolvidas pelo pesquisador ao longo tempo "estão entrelaçados elementos teóricos e modos de operá-los com eles”. Nas linhas a seguir estão presentes esses

\footnotetext{
2 Esse projeto foi desenvolvido no Programa de Pós-Graduação em Educação da Universidade Tiradentes (Unit/SE), que resultou na obtenção do título de mestre em Educação.

3 Projeto desenvolvido no Programa de Pós-Graduação em Educação e Saúde na Infância e na Adolescência da Universidade Federal de São Paulo (Unifesp/SP), resultando na obtenção do título de doutor em Ciências.
} 
entrelaçamentos, que podem ser lidos e interpretados nos resultados de pesquisa que compõem este artigo. Desde já, cumpre registrar que fiz esta rememoração não apenas para expor alguns traços de meu passado, mas para mostrar os tempos e espaços da minha entrada no campo da História da Educação Matemática e do processo de construção teórica do objeto de pesquisa aqui exposto. No fundo, quis mostrar que o tema aqui tratado esteve e está situado no cruzamento de vários caminhos de pesquisas. E mais: com esta rememoração procurei destacar que a trajetória na pesquisa tem sido determinante para a produção deste artigo: da escolha do tema à redação do texto. Da iniciação científica ao doutorado tenho analisado livros escolares de Aritmética para reconstruir uma paisagem do passado educacional do ensino dessa matéria em escolas primárias. Para além de uma história de determinada matéria escolar específica, tenho procurado interpretar algumas histórias lidas nas páginas de livros escolares. Isso tem me permitido perceber que numerosas são as histórias salvaguardadas nesse produto industrial e objeto cultural, que é o livro escolar. Ao longo deste artigo mostrarei como penso o livro escolar enquanto produto industrial e como objeto cultural.

Por ora, basta levarmos em consideração que um livro é mais que um objeto material portador de um discurso redigido ao público. O livro é um objeto cultural que difunde ideias, transmite conceitos, condensa conhecimentos (CHARTIER, 2010). Para além desses elementos, o livro escolar tem outras características. Ele contém e salvaguarda as marcas de um movimento pedagógico, no que concerne a organização e estruturação dos saberes escolares, as escolhas dos métodos de ensino para conduzir uma matéria ou disciplina escolar etc. (CHOPPIN, 2011).

Por assim ser, a escrita deste texto esteve norteada pela seguinte pergunta: que marcas do movimento pedagógico denominado de vaga intuitiva ${ }^{4}$

\footnotetext{
${ }_{4}^{4}$ A vaga intuitiva é entendida como uma corrente pedagógica formada pelas escolhas didáticas e metodológicas para tornar intuitivo o ensino em escolas primárias brasileiras, durante o período de 1870 aos anos de 1920. Tais escolhas ainda se alinhavam às diferentes exigências atribuídas às escolas primárias na formação intelectual e social das crianças. A emergência de novos livros
} 
podem ser lidas nas páginas da trilogia aritmética - Aritmética primária, Aritmética elementar ilustrada e Aritmética progressiva - de Antonio Bandeira Trajano? As pesquisas desenvolvidas da iniciação científica ao doutorado têm oferecido elementos que permitem construir uma resposta para essa questão. Para tanto, inicialmente, precisei saber quem foi Antonio Bandeira Trajano e quais as ações educacionais que o levaram a sentir a necessidade da produção de livros escolares. Para isso, recorri aos escritos de Matos (2004) e jornais da época.

Mais do que informações bibliográficas de Antonio Trajano, jornais da época também possibilitaram acompanhar as vultosas reedições dos seus livros escolares de Aritmética e uma rápida difusão desses livros de norte a sul do país. Ao considerar o contexto pedagógico de produção e difusão da trilogia aritmética, observei que nas páginas dessa trilogia Antonio Trajano dizia "apresentar uma 'nova' maneira de ensinar Aritmética" (TRAJANO, 1885, p. II), seguindo os princípios do método intuitivo. Considerando as palavras do autor, os vultosos números de reedições da trilogia aritmética e a sua rápida difusão, procurei compreender que modelo de ensino intuitivo estava sendo difundido Brasil afora nas páginas da trilogia aritmética de Antonio Trajano. Amparado pelas orientações teórico-metodológicas de autores como Choppin (2007), Lebrun (2007), Gerard e Roegiers (1993) e Valdemarin (2004) foi possível identificar princípios pedagógicos do método intuitivo na condução do ensino de Aritmética. À luz desse aporte teórico-metodológico analisei a trilogia aritmética a partir dos seguintes elementos estruturantes dos livros escolares: capa, contracapa, prefácio, índice, exemplos, exercícios, problemas, imagens, regras, notas.

Por fim, busquei saber quais autores serviram de referências para Antonio Trajano na elaboração da sua trilogia aritmética. Na tentativa de encontrar tais referências, adotei três caminhos metodológicos: $1^{\circ}$ ) olhei para o

escolares é um indicador da conformação de uma ou mais vagas pedagógicas. Veja-se o exemplo do contexto escolar francês. Segundo Chervel (2006, p. 413, tradução livre) "A entrada de autores franceses em aulas sob o Antigo Regime, no século XIX e ainda no século XX, se organiza em várias vagas/ondas sucessivas. Cada série de livro responde à uma exigência de formação de jovens que prevalece em sua época. [...]. Cada uma dessas vagas/ondas deposita sobre as mesas dos alunos uma série de obras marcantes e, por vezes, obras-primas". 
contexto no qual Antonio Trajano estava inserido durante sua formação profissional e como autor de livros escolares; $2^{\circ}$ ) analisei escritos da época de produção, circulação e utilização da trilogia aritmética; $2^{\circ}$ ) fiz um levantamento exaustivo dos livros de Aritmética publicados até 1880 e destinados às escolas primárias e elementares nos Estados Unidos, já que Antonio Trajano era professor de Aritmética na Escola Americana fundada em São Paulo, na década de 1870.

Acredito que todo esse percurso de pesquisa possibilitou alcançar o objetivo geral deste artigo: caracterizar a configuração do modo intuitivo de ensinar aritmética, que foi rapidamente e amplamente difundido Brasil afora a partir da trilogia aritmética de Antonio Bandeira Trajano.

\section{QUEM FOI ANTONIO BANDEIRA TRAJANO?}

De Portugal para o Brasil. Nascido no dia 30 de agosto de 1843, em Vila Pouca de Aguiar, Portugal, Antonio Bandeira Trajano fez o ensino primário e secundário no seu país natal. Aos 14 anos, ele chegou no Brasil e se tornou brasileiro por naturalidade. Alguns anos mais tarde, ingressou no seminário presbiteriano fundado no Rio de Janeiro em 14 de maio de 1867. Como seminarista, entre os anos de 1867 e 1870, Trajano ensinou Geografia e Aritmética nas escolas paroquiais anexas à igreja presbiteriana. Em março de 1873, casou-se com Olympia Bandeira Trajano, em Sorocaba, São Paulo, e juntos tiveram sete filhos (MATOS, 2004).

Da mesa de professor para o púlpito de pastor. Em 10 de agosto de 1876 , Trajano foi elevado o primeiro pastor nacional da Igreja Presbiteriana no Rio de Janeiro (MATOS, 2004). Os três anos de ensino de Aritmética nas escolas paroquiais lhe abriram novos caminhos. Pouco tempo como pastor, ele retornou à São Paulo, em agosto de 1877, para ser professor de Matemática na Escola Americana, fundada em 1870. À época, Mary Parker Dascomb, uma missionária 
americana, estava à frente da cadeira de Matemática e da direção dessa escola. Segundo Matos (2004, p. 68), Mary Dascomb dirigiu Antonio Trajano na preparação "da famosa Aritmética Progressiva, que se tornou célebre nas escolas do Brasil”. Em outubro de 1880, o luso-brasileiro retornou à sua missão pastoral no Rio de Janeiro.

Do púlpito de pastor para as salas de reuniões. Cada vez mais longe das salas de aulas, Trajano desenvolveu outras atividades profissionais. Ele foi o criador e redator chefe do jornal presbiteriano O Puritano, projeto colocado em execução a partir de 8 de junho de 1899, no Rio de Janeiro, com a colaboração de Álvaro Reis, Franklin do Nascimento e Erasmo Braga. Em 1890, ele atuou como conselheiro da administração financeira do Hospital Evangélico Fluminense. Nos anos de 1902, Trajano foi jubilado pelo presbitério do Rio de Janeiro e morreu dia 23 de dezembro de 1921, aos 78 anos.

Das experiências profissionais à produção de livros escolares. Para Matos (2004), as experiências profissionais de Trajano nas escolas paroquiais e na Escola Americana demonstraram a grande necessidade de livros didáticos de Matemática. Dito de outro modo: “o crivo da experiência pedagógica é sempre explicitado como justificativa para a elaboração de livros" (VALDEMARIN, 2010, p. 129). De pastor, Trajano se tornou autor de livros escolares largamente difundidos no Brasil: Aritmética primária ( $1^{\mathrm{a}}$ ed., à venda desde 24 de set. de 1886); Aritmética elementar ilustrada ( $1^{\mathrm{a}}$ ed. publicada desde julho de 1883); Aritmética progressiva ( $1^{\mathrm{a}}$ ed., à venda desde 08 de fev. de 1879); Álgebra Elementar; Álgebra Superior; Chave da Aritmética Progressiva; Chave da Álgebra.

Esses são alguns fatos básicos que permitem compreender tanto as atividades profissionais de Antonio Bandeira Trajano como o contexto de produção dos seus livros escolares, destacando sua trilogia aritmética. 


\section{POR QUE ANALISAR A TRILOGIA ARITMÉTICA?}

Algumas histórias dos livros escolares de Aritmética de Antonio Trajano servem de resposta e de justificativa para essa escolha.

\section{A Aritmética progressiva e a Aritmética elementar ilustrada tiveram sua} primeira edição publicada em 1879 e atravessaram a primeira metade dos Novecentos, atingindo, respectivamente, a $91^{\mathrm{a}}$ edição de 1961 e a $138^{\mathrm{a}}$ de $1960^{5}$. Embora tenham sido publicadas no mesmo ano, essas duas obras obedeceram a uma ordem de publicação e tiveram público almejado. A Aritmética progressiva foi publicada em 8 de fevereiro de 1879 e destinada aos alunos das escolas de ensino secundário e superior. Todavia, somente em meados do século XX ela foi muito usada em escolas públicas. A aprovação da Aritmética progressiva para circular em escolas públicas contou com o auxílio de um ex-aluno e amigo, o jornalista Herculano Ernesto de Gouvêa.

A Aritmética elementar ilustrada foi um livro escolar produzido posteriormente e destinava-se aos alunos dos últimos anos das escolas primárias. Este continha todos os conteúdos da matéria, que deveriam ser trabalhados com os alunos daquelas classes, dispostos segundo a ordem pretendida pelo ensino primário superior, e ilustrações adequadas ao texto. $\mathrm{O}$ grande reconhecimento dessa obra ocorreu através da sua premiação na Exposição Pedagógica (1883) e com a aprovação e adoção pelo governo do Rio de Janeiro em 1902.

Da composição desses dois livros de Aritmética surgiu por volta de 1886 uma obra escolar destinada às séries iniciais, intitulada Aritmética primária. Essa obra teve seu apogeu da década de 80 do século XIX aos anos 20 do século

\footnotetext{
5 Ainda não foi possível saber qual a edição e o ano da última reimpressão da trilogia aritmética. Outras pesquisas carecem de ser realizadas. O que se sabe é que "Antonio Trajano [...] com Aritmética Elementar Ilustrada, obra premiada na Exposição de 1883 do Rio de Janeiro, tornouse um autor nacionalmente conhecido" (BITTENCOURT, 2004, p. 487). Mais que isso: se alguém fosse comprar algum dos livros de Aritmética de Antonio Trajano na Livraria Francisco Alves e, porventura, o vendedor desse uma informação errada ao freguês, o próprio Francisco Alves tratava de corrigir a informação, indicando o lugar de destaque dos livros de Trajano: “Como não temos a 'Aritmética' de Trajano, 'seu' Jéquim? - gritava o velho Alves. Está na primeira estante, primeira prateleira, ao lado da vitrine" (JORNAL DA SEMANA, 1954, p. 6).
} 
XX. De 1886 a 1923, a obra saiu da $1^{\mathrm{a}}$ edição e atingiu a $104^{\mathrm{a}}$ edição. Ou seja, em apenas 37 anos a Aritmética primária teve 104 reedições - quase três edições por ano! No entanto, a partir de 1923 o número de reedições caiu bruscamente. De 1923 a 1947, o livro saiu da 104 a edição para $118^{\text {a }}$ edição. Isto é, em 24 anos apenas 14 edições - menos de uma edição por ano! Dados diametralmente opostos que merecem uma análise mais detalhada. Tal análise não teve espaço na escrita deste texto. Fica, então, para outros estudos.

Cada obra dessa trilogia aritmética teve seu próprio ritmo de reedição. Enquanto na década 1910 a Aritmética progressiva e a Aritmética elementar ilustrava estavam circulando na sua $26^{\mathrm{a}}$ edição e $68^{\mathrm{a}}$ edição, respectivamente, a Aritmética primária alcançava o avultoso número de $79^{\mathrm{a}}$ edição. É fato, porém, que durante o seu período de apogeu (1879-192?), a trilogia aritmética de Antonio Trajano esteve na vida escolar de boa parte da população infantil de diferentes partes do Brasil. Veja a seguir (Fig. 1) um mapeamento da circulação dessa trilogia país afora. No mapa estão sinalizados os Estados por onde pelo menos uma obra dessa trilogia foi difundida, entre 1879 e a década de 1920.

Figura 1 - Um mapeamento da circulação da trilogia aritmética de Antonio Trajano.

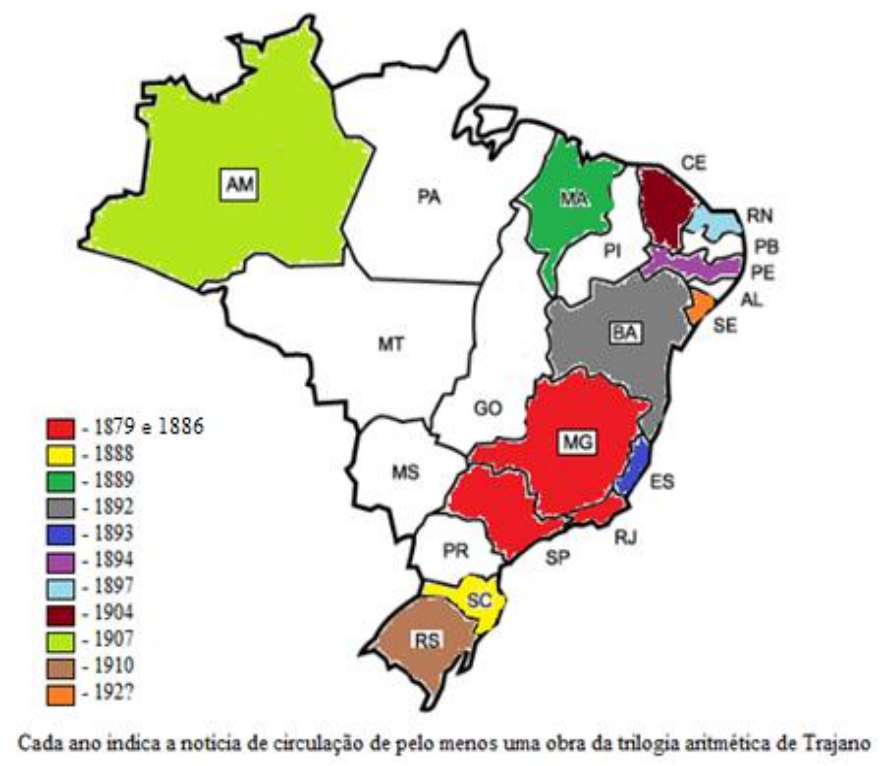

Fonte: Construído pelo autor a partir de relatórios de instrução e notícias de adoção da obra publicadas em diferentes jornais e revistas que circulavam na época. 
Esse mapeamento da circulação da trilogia aritmética de Antonio Trajano, ainda que provisório, pode ser interpretado como uma espécie de "geografia cultural" (DARNTON, 1996), tanto da renovação pedagógica do ensino de Aritmética em escolas primárias brasileiras como da comercialização de um produto industrial.

Do ponto de vista econômico, a circulação de um livro não ocorre por acaso. O livro escolar é um produto manufaturado e comercializado (CHOPPIN, 2011; MUNAKATA, 2012). O preço de cada exemplar da Aritmética primária de Trajano variava entre $\$ 300$ e $\$ 800$ réis. Esse produto da indústria cultural circulava por pelo menos três canais: $1^{\circ}$ ) o correio, pois acrescidos 300 e/ou 500 réis o exemplar poderia ser enviado; $2^{\circ}$ ) o agente de venda, quando em 1886 José Gomes da Silva atuou em Minas Gerais difundindo a Aritmética primária, Aritmética elementar ilustrada e Aritmética progressiva; $3^{\circ}$ ) a via fluvial, utilizada para o transporte de grandes lotes. O envio pelo correio acorria da seguinte maneira: aqueles que quisessem um ou mais exemplares dos livros didáticos de Trajano deveriam escrever uma carta para o autor (no endereço, Caixa do Correio n. 254 na Corte do país, Rio de Janeiro). Na carta deveria conter o montante por cada exemplar e pela sua postagem. Um mil réis era o limite da postagem utilizando selos do correio. $\mathrm{O}$ que significa dizer que pelo correio a obra circulava em pequenos lotes.

Para grandes lotes, Trajano utilizava a via fluvial para fazer circular seus livros. Em 05 de fevereiro de 1891, publicou-se no Diário do Comércio, a notícia de que pela Companhia fluvial Vapor Nacional Camillo saiu um pacote de livros emitido por Antonio Trajano, com destino à cidade de Desterro (atual Florianópolis). 40 réis foi o valor pago. Em 15 de novembro de 1891, um anúncio feito no Jornal do Comércio, do Rio de Janeiro, fez saber que pela Companhia Vapor Nacional Beberibe saiu da capital federal com destino a Pernambuco uma caixa de livros remetida por Trajano. 200 réis foi a quantia paga por esse envio. Muito provavelmente, a via fluvial foi o canal utilizado por Trajano para responder a demanda do Diretor Geral da Instrução Pública de Santa Catarina ao 
enviar 1.000 exemplares da Aritmética primária, em 30 de agosto de $1888^{6}$. Outra demanda também foi atendida ao enviar à Diretoria Geral da Instrução Pública da Bahia 1.00o exemplares da Aritmética elementar ilustrada, por volta de $1892^{7}$.

O correio era um canal que fazia o livro circular com mais rapidez, por isso o elevado valor. O peso do produto enviado também avultava o preço das postagens pelo correio. Do Rio de Janeiro para qualquer lugar do país, o envio de um volume da Aritmética primária, que tinha 67 páginas, custava 300 réis utilizando o correio como canal. Já a Aritmética elementar ilustrada ou Aritmética progressiva, com 136 e 265 páginas respectivamente, o custo da postagem era de 500 réis $^{8}$. Aqueles que compravam pelo correio pagavam por três itens: $1^{\circ}$ ) a postagem da sua carta endereçada ao autor; $2^{\circ}$ ) o valor do livro; $3^{\circ}$ ) a postagem para fazer o livro sair da casa do autor até chegar às suas mãos. Seja como for a forma de difusão da trilogia aritmética, o que se observa é que antes de chegar às salas de aulas as aritméticas de Antonio Trajano tinham um longo caminho a percorrer, trafegando quer por terra quer por mar. Com esses tipos de difusão da trilogia aritmética é possível notar a correlação existente entre a quantidade de livros e o seu meio de circulação.

Do ponto de vista pedagógico, a Figura 1 (acima) permite considerar que de 1879 aos anos 20 do século XX, a trilogia aritmética foi difundida para atender as demandas de renovação do ensino da Aritmética. Como se sabe, à época, a escola primária brasileira passava por uma modernização pedagógica. Para Souza (1998, p. 159), “o método intuitivo foi o símbolo dessa renovação e modernização do ensino". Com o olhar de hoje voltado para aquele contexto de circulação dessa trilogia, pode-se dizer que a quantidade de edição e a rápida difusão fez da

\footnotetext{
${ }^{6}$ Conferir o Relatório provincial que abriu a $1^{\mathrm{a}}$ sessão da $27^{\mathrm{a}}$ legislatura da Assembleia Provincial de Santa Catariana, em 01 de setembro de 1888. Relatório assinado por Augusto Fausto de Souza.

7 Conferir artigo publicado entre as páginas 21 e 23 da Revista do Ensino Primário, Bahia, n. 2, ano 1, dezembro de 1892.

8 Essas informações foram retiradas dos catálogos de venda das livrarias em circulação no ano de 1899.
} 
Aritmética primária um verdadeiro best-seller dos livros didáticos da Aritmética da escola primária brasileira. Isso porque, a Aritmética primária foi a última das três aritméticas publicadas por Trajano e a que mais rápido atingiu avultosos números de reedições num curto espaço de tempo, em relação às outras duas.

No prefácio da $12^{\mathrm{a}}$ edição da Aritmética primária, Antonio Trajano sinaliza que o livro traz uma renovação no método de ensino dessa matéria aos principiantes, porque "as quatro operações sobre números inteiros e frações, [estão] expostas de modo mais claro e simples, indo por meio de lições graduadas, desde o mais fácil até onde o aluno de tenra idade puder compreender e praticar” (TRAJANO, 1895, p. II). Essa organização didático-pedagógica das lições se alinha a certos fundamentos do método de ensino intuitivo, à medida que, segundo Valdemarin (2004, p. 113), “as atividades devem ser feitas gradualmente, dividindo-se a instrução em séries lógicas de exercícios, adotandose as mesmas regras orientadas para um conjunto de pequenos trabalhos, a fim de evidenciar a coerência dos procedimentos".

\section{QUE MODELO(S) DE ENSINO INTUITIVO DE ARITMÉTICA FOI(RAM) DIFUNDIDO(S) BRASIL AFORA A PARTIR DESSES LIVROS ESCOLARES?}

Livro didático: produto industrial e objeto cultural. Enquanto produto industrial, o livro escolar registra as técnicas tipográficas da época, as estratégias de vendas das tipografias, as práticas de produção de um produto, o valor comercial e cultural de um produto de consumo. Como objeto cultural, o livro didático é fruto e elemento configurador da cultura escolar (CHERVEL, 1998), pois a obra didática permite identificar algumas práticas pedagógicas a serem executadas, registra as iniciativas de organização do ensino, oferece indícios e/ou evidências que permitem o pesquisador obter certa "aproximação" do cotidiano escolar de um passado que já nos é muito distante (OLIVEIRA, 2013). 
Retirando-se as poeiras que permaneciam instaladas na Aritmética primária (12 ${ }^{\mathrm{a}}$ edição, 1895$)$, na Aritmética elementar ilustrada (68 ${ }^{\mathrm{a}}$ edição, 191?) e na Aritmética progressiva (68 ${ }^{\mathrm{a}}$ edição, 1935), coloca-se como foco a identificação dos elementos metodológicos que se configuraram como projeto inovador e modernizador para se ensinar aritmética escolar. Olhando as obras por fora, analisei a capa de cada uma das Aritméticas, buscando descrever algumas intencionalidades do autor e da editora na produção dessas obras. Isso porque, segundo Bittencourt (2004, p. 312), “[...] a análise da capa sempre fornece indícios interessantes, desde suas cores e ilustrações até o título e as informações sobre as vinculações com as propostas curriculares”.

Um traço marcante que ocorreu com as três obras foi a presença de ilustração na capa. Trata-se não apenas de figurar uma situação qualquer, mas de ilustrar/representar a ação do homem na natureza. Na capa da Aritmética progressiva há uma figura que ilustra um trem, passando entre montanhas e ao pôr do sol. Já na capa da Aritmética elementar ilustrada e na da Aritmética primária, fica mais clara a representação da participação do sujeito na natureza, talvez com o intuito de figurar a posição de cada indivíduo: enquanto os adultos trabalham, as crianças aprendem brincando com as coisas da natureza. Essas são as situações que evidenciam algumas diretrizes do método intuitivo. A pedagogia moderna de ensino intuitivo tinha como característica básica oferecer dados sensíveis à percepção e observação dos alunos. Segundo Teive (2008),

[...] as crianças deverão expressar do seu modo, sem sujeitar-se a esquemas ou fórmulas dadas de antemão. Ao invés de transmissão pelo/a mestre/a de conceitos, definições e regras [para solucionar os exercícios] busca-se, através da intuição direta, o desenvolvimento das faculdades que, acredita-se, possibilitará aos alunos/as a aquisição, por eles/as próprios/as, do conhecimento [...] (TEIVE, 2008, p. 126).

Evidenciam-se, assim, os papéis da criança na aquisição do conhecimento: trabalhar a mente, controlar as suas emoções e experimentar. Em outras palavras, o conhecimento procede no indivíduo, quando este se conhece, 
isto é, conhece as suas capacidades e limitações. De acordo com a educação dos sentidos, defendida pelo método intuitivo, seria por meio da potencialidade do sujeito, em conhecer a si mesmo, que ele alcançaria um bom desenvolvimento educativo. Por assim postular, reporta-se para a análise das capas de cada uma da trilogia aritmética, as quais trazem ilustrações (Fig. 2).

Figura 2 - Capas da trilogia aritmética de Antonio Trajano.
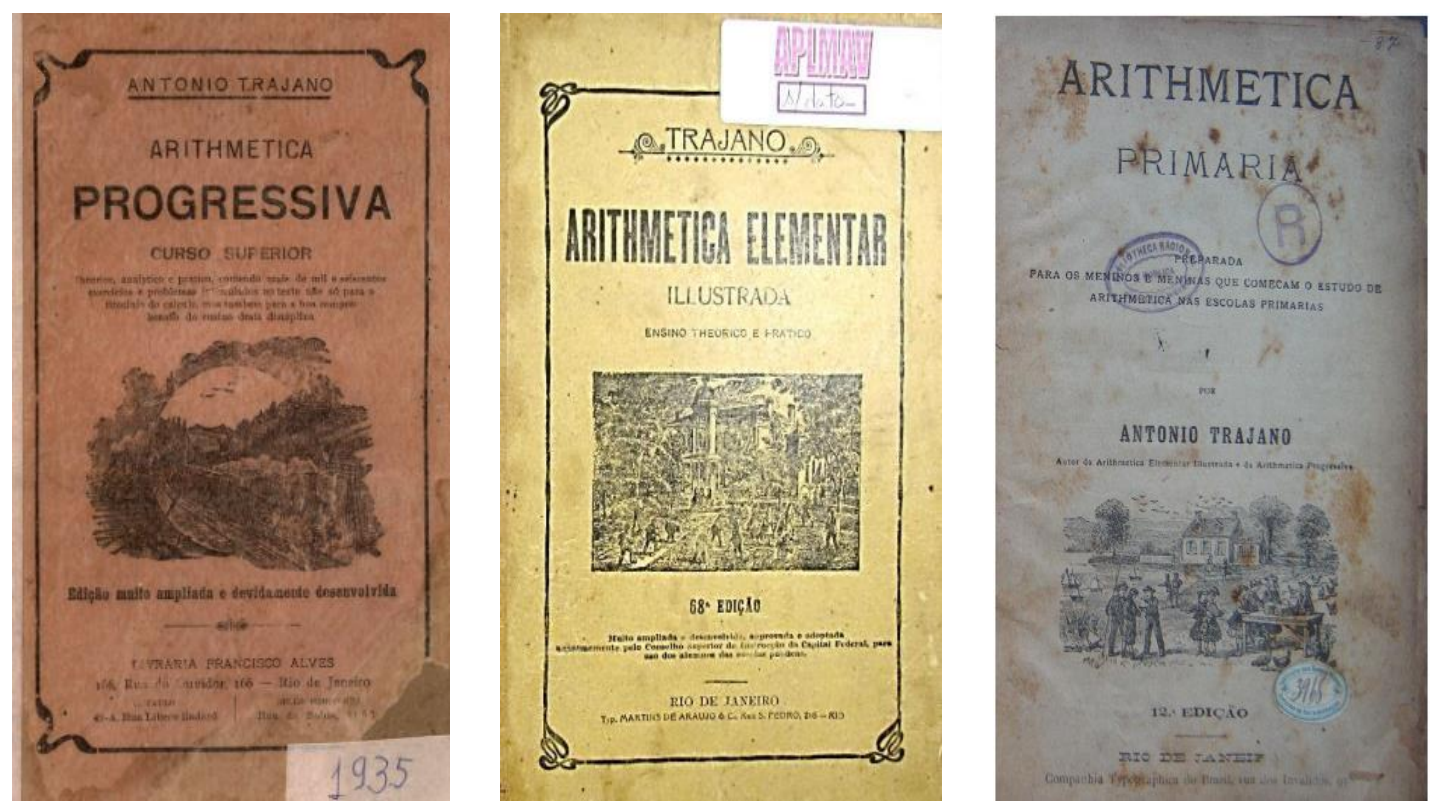

Fonte: Trajano (1935 - esquerda; 191? - centro; 1895 - direita).

Nessas três capas ficam representadas as diferentes posições das crianças, fazendo uso da natureza, de forma atrativa, para adquirir alguns conhecimentos. Na capa da Aritmética elementar ilustrada, algumas dessas crianças estão colhendo flores; outras, pulando corda; outras, com os cadernos (talvez, fazendo algumas anotações); outras, caminhando na lateral de um espaço escolar (no alto direito da ilustração); um homem (que talvez fosse o professor) no lado direito inferior da capa segurando um objeto circular. Na Aritmética primária, algumas crianças estão brincando no lago (na parte superior e esquerda da imagem), enquanto os adultos fazem algum tipo de trabalho. Enfim, ao que a análise indica, essas ilustrações simbolizam alguns princípios do método 
intuitivo: o uso da natureza para extrair o conhecimento e para desenvolver as faculdades inatas no sujeito de julgar, comparar, refletir, perceber e o uso dos sentidos para cheirar, ouvir, tocar e ver as coisas que estão na natureza.

Após essa identificação inicial, considero que a trilogia possa ser lida como documento/monumento que informa sobre um passado educacional, em especial o modo de se ensinar aritmética, dos anos finais dos Oitocentos e início dos Novecentos. Segundo Mesquita (2008, p. 42), em diálogo com Le Goff, todos os documentos "[...] são monumentos que têm roupagens, aparências enganadoras, são montagens". Ao desnudar a trilogia Aritmética das suas roupagens, foi possível recuperar algumas condições de produção dessas obras, bem como as suas significações de duração, de perpetuação - de testemunho de um passado educacional matemático, o da aritmética escolar.

Essa postura teórico-metodológica possibilitou identificar que as obras tiveram suas produções com a incorporação de atrativos metodológicos, os quais propuseram um ensino de Aritmética, de forma perceptiva, gradativa, reflexiva e intuitiva. Tais atrativos foram identificados como: ilustrações; lições graduadas, acompanhadas de exercícios e problemas próprios para cada grau de ensino; ensino teórico e prático. A seguir, o Quadro 1 traz outras informações sobre a trilogia aritmética de Antonio Trajano.

Quadro 1 - Análise externa e interna de alguns caracteres da trilogia aritmética de Antonio Trajano.

\begin{tabular}{|l|l|l|l|}
\hline \multicolumn{4}{|c|}{ Informações sobre a trilogia aritmética de Antonio Trajano } \\
\hline Título da obra & $\begin{array}{c}\text { Aritmética } \\
\text { progressiva }\end{array}$ & $\begin{array}{c}\text { Aritmética } \\
\text { elementar ilustrada }\end{array}$ & $\begin{array}{c}\text { Aritmética } \\
\text { primária }\end{array}$ \\
\hline $\begin{array}{l}\text { Editora e local de } \\
\text { publicação }\end{array}$ & $\begin{array}{l}\text { Livraria Francisco } \\
\text { Alves; Editora Paulo } \\
\text { de Azevedo Ltda - } \\
\text { Rio de Janeiro, rua } \\
\text { do Ouvidor, n. 166. }\end{array}$ & $\begin{array}{l}\text { Livraria Francisco Alves } \\
\text { - Rio de Janeiro, rua do } \\
\text { Ouvidor, n. 166. }\end{array}$ & $\begin{array}{l}\text { Companhia9 } \\
\text { Typographica do } \\
\text { Brazil - Rio de } \\
\text { Janeiro, rua dos } \\
\text { Inválidos, n. 93. }\end{array}$ \\
\hline
\end{tabular}

9 A Companhia Typographica do Brazil surge para substituir a antiga Typographia dos irmãos Laemmert, localizada na rua dos Inválidos, n. 93. 


\begin{tabular}{|c|c|c|c|}
\hline \multicolumn{4}{|c|}{ Informações sobre a trilogia aritmética de Antonio Trajano } \\
\hline Título da obra & $\begin{array}{c}\text { Aritmética } \\
\text { progressiva }\end{array}$ & $\begin{array}{c}\text { Aritmética } \\
\text { elementar ilustrada }\end{array}$ & $\begin{array}{l}\text { Aritmética } \\
\text { primária }\end{array}$ \\
\hline Edição e ano & $68^{\mathrm{a}}$ edição, de 1935. & $68^{\mathrm{a}}$ edição, de $191 ?$ & $12^{\mathrm{a}}$ edição, 1895 \\
\hline $\begin{array}{l}\text { Número de } \\
\text { páginas }\end{array}$ & 265 páginas. & 136 páginas. & 64 páginas. \\
\hline $\begin{array}{l}\text { Quantidade de } \\
\text { itens de } \\
\text { conteúdos }\end{array}$ & 43 conteúdos. & 72 conteúdos. & 13 conteúdos. \\
\hline $\begin{array}{l}\text { Quantidade de } \\
\text { ilustrações }\end{array}$ & 65 ilustrações. & 59 ilustrações. & 43 ilustrações. \\
\hline $\begin{array}{l}\text { Preço de custo de } \\
\text { um exemplar }{ }^{10}\end{array}$ & $5 \$ 000$ & $2 \$ 000$ & $\$ 500$ \\
\hline Dimensões & $\begin{array}{l}19,5 \text { cm de } \\
\text { comprimento; } 14,5 \\
\text { cm de largura; e } 1,5 \\
\text { cm de espessura. }\end{array}$ & $\begin{array}{l}20,5 \text { cm de } \\
\text { comprimento; } 14,5 \mathrm{~cm} \\
\text { de largura; e } 1,0 \mathrm{~cm} \mathrm{de} \\
\text { espessura. }\end{array}$ & $\begin{array}{l}\text { Não sendo } \\
\text { possível informar, } \\
\text { pois se tem essa } \\
\text { obra digitalizada. }\end{array}$ \\
\hline
\end{tabular}

Fonte: Trajano $(1935,191 ?, 1895)$.

Essa análise geral da trilogia revela uma brusca variação de preços entre as obras. Esse fato talvez estivesse ligado ao número de páginas de cada livro ou ao material utilizado pela editora na produção. Além disso, também é possível conjecturar que a variação de preços estivesse correlacionada com o quantitativo de ilustrações. Algumas ilustrações foram repetidas nas três obras e nos mesmos tópicos, por exemplo, nos exercícios: de soma (três ilustrações); de subtração (duas ilustrações); de multiplicação (uma ilustração); e de divisão (três ilustrações); de frações (quatro ilustrações); e do sistema métrico decimal (cinco ilustrações). Talvez o autor tenha optado pela repetitividade das ilustrações, para que os alunos pudessem recordar os pontos estudados na série anterior.

${ }^{10}$ Esses preços foram extraídos da capa de fundo da Aritmética elementar ilustrada, da $72^{\mathrm{a}}$ edição, [19??]. Assim, o valor da primeira obra ( 5 \$0oo) era na sua $36^{\mathrm{a}}$ edição; o da segunda obra ( $2 \$ 000)$ era na sua $72^{\mathrm{a}}$ edição; e o da última obra $(\$ 500)$ era na sua $79^{\mathrm{a}}$ edição. Não foi possível identificar o ano de cada uma dessas edições. Esses preços permaneceram assim até 1920, é o que está registrado na página 59, tratando do catálogo de venda dos livros didáticos da Livraria Francisco Alves. 
Olhando as obras por dentro, no que concerne os aspectos formais como exercícios, ilustrações e os conteúdos a serem ensinados, destaco a presença de elementos metodológicos do ensino intuitivo. Esse modo de ensinar se contrapõe a uma metodologia "[...] alicerçada exclusivamente na memória, priorizada pela abstração, que valoriza a repetição em detrimento da compreensão e que impõe conteúdos sem exame e discussão" (VALDEMARIN, 1998, p. 67).

As ilustrações foram distribuídas em pontos diferentes e com dessemelhantes quantidades. A variedade de exposição com que as ilustrações foram incorporadas nas Aritméticas evidencia informações relevantes para o que se quer saber. Na Aritmética elementar ilustrada, o grande contingente das 59 ilustrações é encontrado nas páginas dedicadas ao Sistema Métrico Decimal -14 ilustrações. Esse quantitativo representa aproximadamente $24 \%$ do total de ilustrações que compõem a obra. Já a Aritmética progressiva, nesse mesmo tópico, tem apenas duas ilustrações, o que representa aproximadamente $3 \%$. O maior quantitativo de ilustrações que compõem essa obra permanece presente nos seguintes tópicos: Superfície; Linha; A Reta; Ângulos; Polígonos; Circunferência e Círculo; Áreas das Figuras Planas; e Relação de Pitágoras. Nesses conteúdos, constam 46 ilustrações, o que resulta em aproximadamente $70,8 \%$ das ilustrações desse livro.

Segundo Gérard e Roegiers (1993, p. 56) "o recurso às ilustrações se revela indispensável para a aprendizagem a tal ponto que se suprimir a ilustração, a compreensão do conteúdo torna-se impossível”. No caso da trilogia aritmética, identificam-se dois tipos de figuras utilizadas para dar a instrução aritmética. Inicialmente, as ilustrações apresentam-se como recurso didático. São ilustrações que participam ativamente da construção do saber. Essas têm a função de induzir o aluno na construção do saber. A ilustração como recurso didático é caracterizada quando o aluno é colocado em situação de busca das respostas para os problemas. Uma ilustração como recurso didático "permite o aluno acessar" o saber escolar. Ou seja, antes do anúncio de uma definição ou de uma regra a ilustração permite ao aluno entrar na matéria, entrar no saber para responder às 
questões construídas a partir da figura. No primeiro momento, o aluno realiza um trabalho analítico e sintético das informações contidas nas ilustrações. Este tipo de ilustração está presente apenas nas quatro operações fundamentais da Aritmética primária e da Aritmética elementar ilustrada.

Mas há ainda as figuras como recurso ilustrativo. Tratam-se de figuras que ilustram os conteúdos, as definições. Elas têm como função mediatizar as relações entre o texto e as informações ilustradas. Falam-se de figuras ilustrativas que "dão a ver" as explicações narrativas. Este tipo de figura está presente apenas nos problemas, nas demonstrações das definições, nos exemplos das três obras.

Pergunto: as figuras são utilizadas somente para acessar e/ou ilustrar os saberes aritméticos? Não. As ilustrações exigem e ao mesmo tempo ajudam os alunos a desenvolverem vários saberes-fazer: saber-observar, saber-examinar, saber-decompor, saber-compor, saber-classificar, saber-criar ligações entre as informações, saber-identificar as diferenças, enfim saber-decodificar uma figura para construir e adquirir os saberes aritméticos. Aqui estão exemplos de saberes escolares (trans)formados no interior da própria escola. São saberes que emergem a partir dos direcionamentos epistemológicos e didáticos da pedagogia moderna de ensino intuitivo. Saberes frutos do postulado pestalozziano de que "não existe saber sem saber-fazer" (PESTALOZZI, 2013, [1801]).

A distribuição das figuras na trilogia aritmética permite constatar que nas dinâmicas ilustração versus definição, ilustração versus demonstração, ilustração versus problemas a marcha didática é bem concebida. Refiro-me à uma didática que organiza os saberes aritméticos a partir de uma marcha intuitiva. Processo de ensino que induz o aluno a constatar que os saberes não são sempre resultados de um simples contato com o real (realidade representada pelas figuras), mas da passagem desse real para abstrato. Em outras palavras, o papel epistemológico e didático das ilustrações é permitir ao aluno construir seu próprio modelo de passagem do concreto ao abstrato.

A grande presença de ilustração na composição da trilogia aritmética é reveladora. A pedagogia moderna de ensino intuitivo defendia a premissa de que 
o conhecimento deveria ser adquirido pelas crianças, de forma intuitiva e reflexiva. Entretanto, fazia-se necessário possibilitar os meios adequados que despertassem as crianças para os atos de intuir e refletir. O uso de ilustrações seria um dos dispositivos didáticos almejados. As ilustrações eram indicadas para a realização da prática da conversação: o professor perguntava e os alunos observavam, intuíam, refletiam e, por fim, respondiam.

Segundo Calkins (1886, p. 33), “[...] a conversação em casa [ou na escola] acerca de objetos de uso diário ordinariamente interessará os meninos. [...]. Induz o pequeno a discorrer sobre as coisas que vê, [...] a formular perguntas a respeito delas, [...]”. A ação pedagógica do professor também seria fundamental. Em outras palavras, o professor deveria empenhar-se "[...] em conseguir dos alunos que se pronunciem acerca de tudo o que ocupar a conversa" (CALKINS, 1886, p. 34). O que daria o norte a essa conversa seria tudo aquilo que estava sendo representado nas e pelas coisas concretas ou por meio das ilustrações.

Ao analisar cada obra separadamente são observadas outras permanências comuns. A Aritmética primária foi dividida em tópicos, ou melhor, em quantidades de itens de conteúdos. Para cada item, tem-se a definição do que se estudaria. Explicações simples e curtas também fazem parte do processo metodológico adotado por Trajano para ensinar Aritmética. Como exemplo dessas constatações, observei que, antes do estudo de numeração, a Aritmética primária abordou a diferenciação entre "Quantidade, Unidade e Número”. De acordo com a obra, quantidade é uma porção de alguma coisa que se pode pesar, medir ou contar; unidade significa uma só coisa por onde se começa a contar as quantidades; número é o que exprime quantas unidades contém uma quantidade. Tais definições também se fazem presentes nas outras duas obras.

Na maioria das explicações havia um ou dois problemas seguidos de solução. Após isso, os livros dispunham de uma variedade de exercícios de aplicação para que os alunos pudessem praticar o que lhes havia sido ensinado. Os exercícios de aplicação foram distribuídos na Aritmética primária de dois 
modos: alguns para serem resolvidos, utilizando-se a prática das regras dos conteúdos, as quais os exercícios acompanhavam; e outros para serem trabalhados oralmente. Essas diferentes maneiras de responder os exercícios podem ser considerados como processos de sistematização e racionalização das práticas do saber contar e calcular.

A maioria dos exercícios são destinados a uma utilidade no nível estritamente escolar. Do oral para o escrito, do mental para o manual, os exercícios presentes nesse livro evoluem no ritmo progressivo do desenvolvimento intelectual da criança na aquisição dos saberes. Não escreve os números e nem realiza os cálculos antes do saber contar oralmente e do saber calcular mentalmente. Configura-se assim um processo de ensino que segue a marcha de encadeamento dos saberes aprendidos. A ordem do ensino está relacionada à ordem da mentalidade de quem aprende. Tal é a organização dos saberes que caracterizam a didática dos exercícios de aritmética praticados na escola primária brasileira, lida nas páginas da Aritmética primária, do final do século XIX. Os conteúdos que a compuseram foram: numeração; operações fundamentais (soma, subtração, multiplicação e divisão); propriedades dos números (primos e múltiplos, critérios de divisibilidade); máximo divisor comum - MDC; mínimo múltiplo comum - MMC; frações; números decimais; sistema métrico.

A Aritmética progressiva e a Aritmética elementar ilustrada seguiram a mesma dinâmica de exposição da matéria: divididas em tópicos, por meio de definições e alguns problemas solucionados; presença de numerosos exercícios para serem trabalhados. Em cada um desses pontos foi possível evidenciar que a trilogia carregava elementos que se caracterizavam como princípios da metodologia intuitiva. As definições de números abstratos e de números concretos, trazidas pela Aritmética primária, testemunham parte dessa observação. De acordo com a obra, os números abstratos são os que não estão unidos a nome algum: 4, 5, 7, 45 etc. Já os números concretos são aqueles que estão unidos ao nome dos objetos para exprimir seu valor: 4 lápis, 5 livros, 7 
maçãs, 45 peras etc. Na pedagogia de ensino prático e intuitivo, ensinar número, utilizando-se objetos 'concretos', seria a forma mais intuitiva de se estimular a percepção sensorial da criança. Ao contar, por exemplo, lápis, moedas, botões, bolas, livros, maçãs etc., o conhecimento de número caracterizava-se por meio da percepção imediata e espontânea de enumerar os objetos. Tal princípio foi seguido pelos exercícios presentes na trilogia aritmética.

As atividades contidas em cada ponto estudado fornecem indícios para se avaliar a qualidade do texto no que se refere às possibilidades de apreensão do conteúdo. Não foram analisados todos os exercícios presentes em cada livro escolar aqui examinado, pois só a Aritmética progressiva apresenta 1.600 exercícios e problemas para serem solucionados. Entretanto, ao se examinar as atividades da trilogia, de modo geral, ressaltou-se a presença de elementos que sinalizam em direção à pedagogia intuitiva. Ao oferecer alguns problemas com a solução e outros para serem solucionados, o autor procurou expor como utilizar aquelas regras e definições. À medida que o autor utilizava esse artifício metodológico, ele possibilitava que o aluno observasse e praticasse as regras aritméticas às quais a questão estava vinculada. Os primeiros problemas propostos se iniciavam com o mesmo grau de dificuldade que aqueles já solucionados, permitindo que o raciocínio lógico matemático fosse construído de maneira perceptiva, reflexiva, intuitiva e gradativa.

Os exercícios iam aumentando a dificuldade gradativamente de modo que os alunos pudessem identificar a coerência dos procedimentos aritméticos que lhes eram ensinados. Esse tipo de prática de exercícios percorre o princípio do método intuitivo, que no ensino deveria ocorrer "[...] do simples ao complexo; do que se sabe para o que se ignora; dos factos, para as causas; das coisas, para os nomes; das ideias, para as palavras; dos princípios, para as regras" (CALKINS, 1886, p. 3). A diversidade de atividades práticas revela o intento do autor em permitir que os alunos conhecessem a sua variada aplicação. De outro modo, Calkins salientou que o avanço nos estudos, seguindo os princípios do método intuitivo, seria realizado "[...] segundo a capacidade e aproveitamento dos 
alunos" (CALKINS, 1886, p. 244). Calkins continuou a dizer que o ensino deveria levar em consideração "[...] o espírito infantil e os processos por que adquire o saber [...]", tendo o cuidado de não "[...] obter das crianças que vençam muito terreno de uma vez" (CALKINS, 1886, p. 270).

Observei, assim, que alguns traços metodológicos utilizados por Antonio Trajano revelam o modo intuitivo de se ensinar aritmética. Um deles foi evidenciado na leitura do índice de cada obra, bem como na própria distribuição dos seus conteúdos (LEBRUN, 2007). As obras da trilogia aritmética seguiram os mesmos procedimentos metodológicos de organização dos conteúdos: um aumento gradativo da dificuldade; conteúdos que abordavam situações cotidianas; uma ligação entre os itens de conteúdos, dentre outras características. Essa sistematização dos conteúdos que compõem a trilogia evidencia o método pretendido para o desenvolvimento da matéria escolar.

Na proposta de Trajano é possível identificar a existência de diferentes caminhos para fazer os alunos adquirir os saberes aritméticos de modo intuitivo. Na análise da trilogia foram identificados os seguintes caminhos: a organização das atividades e ordenação dos conteúdos. Para Teive (2008, p. 124), "[...] as lições deveriam ser organizadas a partir de coisas e de objetos familiares às crianças, progredindo para coisas distantes do seu universo [...]”. Já para a ordenação dos conteúdos, o “[...] essencial na escolha dos conteúdos de cada lição era que possibilitassem a construção do 'saber útil', considerado necessário para o indivíduo mover-se no seu cotidiano, saber esse produzido a partir da ação e do trabalho". Com esses dois caminhos presentes na trilogia, torna-se possível que pensar que ao seguir por pelo menos um desses caminhos os alunos passariam das intuições confusas às percepções claras e das representações para as abstrações.

Johann Pestalozzi mostrou o poder do uso de um método (que é o intuitivo), que assim se lê: 


\begin{abstract}
Quem quer que se aproprie do método, seja uma criança, um jovem, um homem ou uma mulher, chegará sempre em seus exercícios a um ponto que solicitará particularmente sua individualidade: ao captá-lo e desenvolvê-lo essa pessoa fará emergir em si mesma, forças e meios que lhe permitirão superar, em grande medida, necessidade de ajuda e apoio em sua formação que nesta etapa continua sendo indispensável para outros, e estará em uma situação de percorrer e completar, com passos seguros e autônomos, o caminho de sua formação (PESTALOZZI, 1801 apud SOËTARD, 2010, p. 24).
\end{abstract}

A metodologia de ensino que faz uso de ilustrações e da prática para o desenvolvimento da inteligência do indivíduo, assim como de dispositivos pedagógicos para aquisição do conhecimento, é o método intuitivo. Pela análise realizada, é possível inferir que Antonio Trajano possibilitou que os alunos e os professores brasileiros daquela época tivessem acesso às novas maneiras de se aprender aritmética, acompanhando os padrões educacionais de países estrangeiros, nomeadamente os dos Estados Unidos. Do ponto de vista da produção desses livros,

[...] cabe assinalar que os livros escolares estão sujeitos a constantes transformações, alternando-se períodos de mudanças lentas e graduais com momentos de transformações mais intensas e rápidas. Além disso, sofrem a repercussão dos movimentos de reforma pedagógica e das novas metodologias que acompanham tais movimentos, sendo também influenciados pelas transformações técnicas que afetam a indústria editorial e pelas mudanças políticas, econômicas e culturais de alcance nacional e internacional (ROCHA; SOMOZA, 2012, p. 24-25).

Nesse sentido, veja-se a relevância de enxergar o livro escolar como objeto cultural. Não obstante, essa trilogia aritmética pode ser compreendida enquanto objeto de diferentes dimensões culturais que difundiu um projeto reformador para o ensino de aritmética. Entendo, ainda, o livro escolar como um dispositivo capaz de referenciar pedagógica e culturalmente uma sociedade que faz seu uso. Afinal, uma obra didática é um objeto cultural adequado para se alcançar determinados sujeitos, possibilitando que esses indivíduos ultrapassem suas limitações. 
A análise revelou que a trilogia aritmética assumiu algumas dimensões culturais: marcou o início da produção de livros escolares com diferentes tipos de graduação, abordando o mesmo saber escolar; fez circular um modo de ensinar Aritmética que ficou denominado como inovador e modernizador; e, por fim, disseminou no Brasil a cultura educacional ancorada na pedagogia moderna de ensino intuitivo, amplamente difundida na Europa e nos Estados Unidos.

\section{QUAIS FORAM AS REFERÊNCIAS DIDÁTICO- PEDAGÓGICAS DE ANTONIO BANDEIRA TRAJANO?}

Por ser um objeto cultural, o livro didático é produzido em um contexto histórico, geográfico e pedagógico determinado. Isso implica, segundo Choppin (2011, p. 19), que "a análise da literatura escolar necessita então que seja levado em conta os contextos nos quais ela é concebida, produzida e difundida, mais também utilizada e recebida”. Sabe-se que as obras de Antonio Trajano foram escritas em um contexto pedagógico de constantes transformações. De 1870 a 1886, sete projetos de reformas escolares foram apresentados à Assembleia dos Deputados da Corte, no Rio de Janeiro ${ }^{11}$. Visando o progresso do Brasil em relação às nações da Europa e aos Estados Unidos, os dirigentes da educação acreditavam que esse progresso passaria pela escolarização da população.

No século XIX, países como Alemanha, Suíça e Estados Unidos assinalaram seus vetores de reforma educacional para uma pedagogia centrada nos pressupostos do método intuitivo. Nos Estados Unidos, por exemplo, esse método foi inicialmente identificado pela expressão object teaching. Entretanto, a vulgarização do método intuitivo naquele país ocorreu através da expressão

\footnotetext{
${ }^{11}$ Destacam-se os projetos de reforma escolar de Paulino José Soares de Souza (1870); Antonio Cândido Cunha Leitão (1873); João Alfredo Corrêa de Oliveira (1874); Carlos Leôncio de Carvalho (1879); Rui Barbosa (1882-1883); Almeida de Oliveira (1882); e Barão de Mamoré (1886) (MACHADO, 2005).
} 
object lesson (SOUZA, 2005). Ainda considerando o contexto estadunidense, "ao longo do século XIX, os princípios de Pestalozzi consubstanciados no método intuitivo foram apropriados de forma peculiar para a sua adoção na escola primária graduada" (SOUZA, 2005, p. 24).

Comumente chamada de pedagogia moderna, tal pedagogia se caracterizava a meu entender por alguns princípios: primazia da educação em detrimento à instrução; formação integral do espírito humano, nos aspectos morais, intelectuais e físicos a partir da experiência individual; ensino que visa a iniciativa da atividade do espírito humano, provando o desenvolvimento das faculdades naturais (observação, julgamento, raciocínio etc.); método de ensino que repousa nas leis psicológicas do aprendiz; princípio fundamental de todo ensino é que o conhecimento deve chegar primeiro ao entendimento por via da intuição e não da memorização (da sensação ao intelecto); ensino experimental que coloca o aluno em contato direto com as realidades (OLIVEIRA, 2017).

A circulação do método intuitivo ocorreu inicialmente no Brasil nas escolas privadas fundadas pelos missionários presbiterianos, como correlato das lições de coisas. Uma das primeiras escolas a trabalhar com essa metodologia foi a Escola Americana, fundada em São Paulo (HILSDORF, 2007; SCHELBAUER, 2003). Essas informações foram fundamentais na elaboração de uma hipótese de pesquisa. Vale lembrar que a construção de hipótese é uma das práticas próprias do ofício do historiador (CHARTIER, 2014). Ela é de início uma resposta a uma questão. Por assim ser, perguntei: quais as referências didático-pedagógicas de Antonio Trajano? A princípio, trata-se de uma questão de difícil resposta, porque o nosso autor não fez menções às suas referências.

Entretanto, ao olhar para o contexto no qual Antonio Trajano estava inserido durante sua formação profissional (pastor, conselheiro administrativo, professor) e como autor de livros didáticos, considerei o fato de o luso-brasileiro ter trabalhado como professor de Aritmética na Escola Americana, em São Paulo, quando começou a redigir suas obras didáticas. Assim, tomei como hipótese de partida que Antonio Trajano tinha contato com livros escolares dos Estados 
Unidos, o que lhe favoreceu na preparação das suas obras didáticas, em especial a sua trilogia aritmética. A fim de confirmar ou refutar essa afirmação, utilizei dois caminhos metodológicos: $1^{0}$ ) analisei escritos da época de produção, circulação e utilização da trilogia aritmética; $2^{\circ}$ ) fiz um levantamento exaustivo dos livros de Aritmética publicados até 1880 e destinados às escolas primárias e elementares nos Estados Unidos.

No jornal A província de São Paulo, de 17 de outubro de 1879, publicouse uma matéria intitulada "Utilidade do estudo da Aritmética", com autoria de João Ribeiro de Carvalho Braga. O autor destacou que na escola brasileira a aversão à Aritmética tinha duas causas: por ser considerada uma matéria sem importância e pela falta de livros escolares práticos. Como contraponto para mudar aquela realidade brasileira, João Braga citou os avanços intelectuais dos estadunidenses devido a importância que eles davam ao ensino das Matemáticas.

O grande adiantamento intelectual do povo norte-americano é em parte devido ao desenvolvimento que dão ao ensino, e especialmente ao ensino das Matemáticas. Os meninos e meninas saem das escolas públicas sabendo resolver qualquer problema de Aritmética ou Álgebra.

O apreço que ali se dá ao ensino dos números pode ser avaliado pelo avultado número de exemplares que ali há em circulação. O compêndio de Ray já está [na] MILÉSIMA edição; o de Greenleaf, no fim de seu livro diz que um milhão e seiscentos mil exemplares estão em circulação. Thomson, em 1875, publicou a sua $23^{\mathrm{a}}$ edição. Davies, Peck e Venable estão sendo reimpressos constantemente (A PROVÍNCIA..., 1879, p. 2, grifo nosso).

Na tentativa de supressão da segunda causa da aversão à Aritmética no Brasil, João Braga disse:

Quanto à segunda causa, julgamos que ela será também em breve removida com aparição da Aritmética Progressiva do sr. Antonio Trajano. Este compêndio tem todos os predicados para satisfazer perfeitamente a necessidade que sentimos e desenvolverá entre nós o gosto pela ciência dos números, fazendo os discípulos estudar com gosto o que antes faziam com sacrifícios, como já tive ocasião de verificar (A PROVÍNCIA..., 1879, p. 2, grifo nosso). 
No mesmo jornal e na mesma edição de 17 de outubro de 1879 , um noticiário intitulado "Um bom livro", com autoria desconhecida, fez circular as seguintes informações:

Temos à vista um interessante volume de cerca de 300 páginas nitidamente impresso nas oficinas do Livro Verde, nesta capital.

É a Aritmética Progressiva do ilustrado professor sr. Antonio Trajano, que nos dá um livro de alta valia para o ensino prático das escolas.

Não conhecemos um tratado de aritmética tão prático e tão completo entre os publicados no país.

O autor amoldou o seu livro pelos melhores compêndios americanos, que como é sabido possuem em alto grau o tino prático do ensino (A PROVÍNCIA..., 1879, p. 2, grifo nosso).

Realmente, Antonio Trajano era muito conhecido no cenário pedagógico brasileiro do final do século XIX não só pelo sucesso de suas aritméticas, mas também por ser um imitador do modelo estadunidense de ensino da Aritmética. Veja o que circulou em outra matéria jornalística da época:

\begin{abstract}
Aritmética elementar ilustrada por Antonio Trajano. O autor já é muito conhecido por um tratado de aritmética [a Aritmética progressiva], imitado de um sistema americano, que tem alcançado grande sucesso entre nós. A Aritmética elementar que temos presente é vasada [sic] nos mesmos moldes do tratado (BRAZIL, 1883, p. 2, grifo do autor).
\end{abstract}

Vê-se então que a hipótese inicial ganhou indícios com essas três matérias jornalísticas. A primeira mencionou os nomes dos autores dos livros didáticos de Aritmética que estavam em ampla reedição e circulação nos Estados Unidos. A segunda, por sua vez, afirmou que Antonio Trajano amoldou o seu livro pelos melhores livros americanos. A terceira reconheceu o sucesso das obras de aritmética de Antonio Trajano vertidas na prática da imitabilidade do modelo americano de ensino da Aritmética. Seguindo os rastros deixados por esses indícios, fiz um levantamento dos livros didáticos dos autores mencionados por 
João Braga. No Quadro 2, seguem os dados encontrados:

Quadro 2 - Livros didáticos de Matemática circulando nos Estados Unidos em 1880.

\begin{tabular}{|c|c|c|}
\hline \multicolumn{3}{|c|}{ Livros didáticos de Matemática nos EUA em 1880} \\
\hline Autor & Coleção & Alguns títulos dos livros didáticos \\
\hline $\begin{array}{l}\text { Joseph Ray } \\
(1807-1855)\end{array}$ & $\begin{array}{l}\text { Ray's } \\
\text { Mathematical } \\
\text { Series }\end{array}$ & $\begin{array}{l}\text { New Primary Arithmetic; New Intellectual Arithmetic; } \\
\text { New Practical Arithmetic; Keys to Ray's new } \\
\text { Artihmetics Intellectual and Practival; New Elementary } \\
\text { Algebra; Key to Ray's Algebra; Geometry and } \\
\text { Trigonometry etc. }\end{array}$ \\
\hline $\begin{array}{l}\text { Benjamin } \\
\text { Greenleaf } \\
(1786-1864)\end{array}$ & $\begin{array}{l}\text { Greenleaf's } \\
\text { Mathematical } \\
\text { Series }\end{array}$ & $\begin{array}{l}\text { New Primary Arithmetic; New Intellectual Arithmetic; } \\
\text { New Practical Arithmetic; New Elementary Algebra; } \\
\text { New Elementary Geometry; Elements of Geometry; } \\
\text { Elements of Trigonometry; Geometry and } \\
\text { Trigonometry; Keys to the Practical Arithmetic, } \\
\text { Elementary Algebra, Geometry and Trigonometry etc. }\end{array}$ \\
\hline $\begin{array}{l}\text { James Bates } \\
\text { Thomson } \\
(1808-1883)\end{array}$ & $\begin{array}{l}\text { Thompson's } \\
\text { Mathematical } \\
\text { Series }\end{array}$ & $\begin{array}{l}\text { New Illustrated table book, or Juvenile Arithmetic; New } \\
\text { Rudiments of Arithmetic; New Practical Arithmetic; } \\
\text { Key to new Practical Arithmetic; Complete Intellectual } \\
\text { Arithmetic; New Practical Algebra; Key to new } \\
\text { Practical Algebra etc. }\end{array}$ \\
\hline $\begin{array}{l}\text { Charles Davies } \\
(1798-1876)\end{array}$ & $\begin{array}{l}\text { Davies and } \\
\text { Peck's national } \\
\text { course in } \\
\text { Mathematics }\end{array}$ & $\begin{array}{l}\text { Primary Arithmetic; Intellectual Arithmetic; Elements } \\
\text { of Written Arithmetic; Pratical Arithmetic; Key to } \\
\text { Practical Arithmetic; New Elementary Algebra; Key to } \\
\text { Elementary Algebra; Elementary Geometry and } \\
\text { Trigonometry etc. }\end{array}$ \\
\hline $\begin{array}{l}\text { William Guy } \\
\text { Peck } \\
(1820-1892)\end{array}$ & $\begin{array}{l}\text { Davies and } \\
\text { Peck's national } \\
\text { course in } \\
\text { Mathematics }\end{array}$ & $\begin{array}{l}\text { First Lessons in Numbers; Elementary Arithmetic; } \\
\text { Manual of Practical Arithmetic; Complete Arithmetic; } \\
\text { Manual of Algebra; Manual of Geometry etc. }\end{array}$ \\
\hline
\end{tabular}

Fonte: Construído pelo autor a partir de alguns exemplares originais desses livros didáticos encontrados na Bibliothèque Diderot de Lyon, na França, de catálogos de livrarias estadunidenses e de exemplares que fazem parte do acervo particular do autor deste texto.

Ao analisar alguns desses livros didáticos americanos de Aritmética, e em seguida compará-los com a trilogia aritmética de Antonio Trajano, os indícios transformaram-se em evidências. As Figuras 3, 4, 5 e 6, a seguir, são os traços mais evidentes que a História da Educação Matemática no Brasil conhece das apropriações do modelo de ensino norte-americano por Antonio Trajano na elaboração da sua trilogia aritmética. Tratam-se de apropriações de Trajano dos 
seguintes livros: Elementary arithmetic - oral and written, de Willian Guy Peck, de 1878, e A primary arithmetic - for first and second grades (years), for third, de Edward Olney, de 1880.

Figura 3 - Apropriações de Peck por Trajano.


Fonte: À esquerda (EUA) - Peck (1878, p. 45); à direita (Brasil) - Trajano (1895, p. 17). 
Figura 4 - Apropriações de Peck por Trajano.
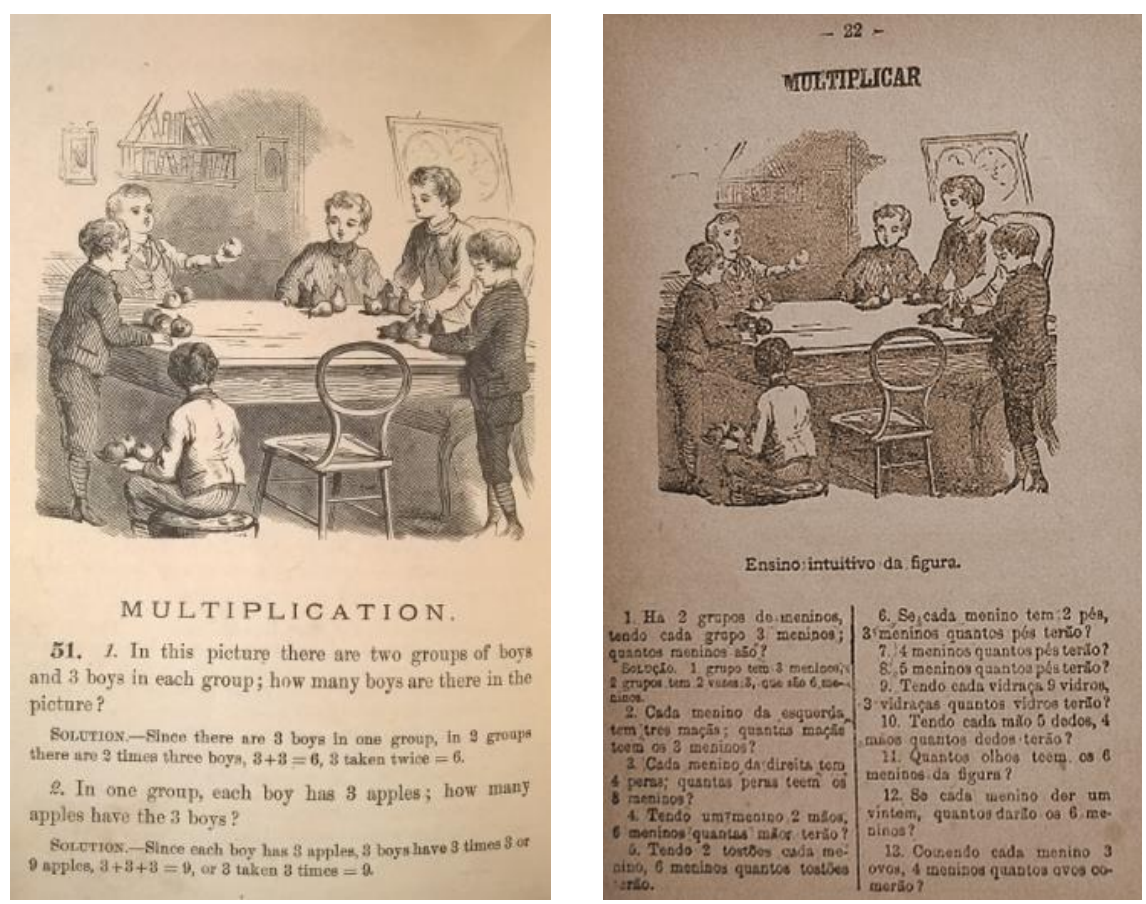

Fonte: À esquerda (EUA) - Peck (1878, p. 6o); à direita (Brasil) - Trajano (1895, p. 17).

Figura 5 - Apropriações de Olney por Trajano.


Fonte: À esquerda (EUA) - Olney (1880, p. 5); à direita (Brasil) - Trajano (191?, p. 33). 
Figura 6 - Apropriações de Olney por Trajano.


Fonte: À esquerda (EUA) - Olney (1880, p. 25); à direita (Brasil) - Trajano (191?, p. 40).

Esses exemplos são suficientes para evidenciar apropriações de livros escolares estadunidenses por Antonio Trajano. A maioria das ilustrações presentes na trilogia aritmética de Antonio Trajano pode ser identificada nos livros de Aritmética de Willian Guy Peck, de 1878; e de Edward Olney, de 1880. Um estudo mais exaustivo sobre essas apropriações pode ser lido em Oliveira (2017).

Cumpre dizer, então, que foi nessa imbricação de referências dos livros didáticos dos Estados Unidos que Antonio Trajano preparou a sua trilogia aritmética. Vou mais além: levanto a hipótese de que toda a produção de livros didáticos dos EUA presente no Quadro 2, tenha servido de referência para o lusobrasileiro na elaboração das suas obras escolares. Segundo Valente (2007, p. 165), "Trajano ainda parece ter sido o introdutor, no ensino de matemática no Brasil, do livro do professor". Falam-se dos livros "Chave da aritmética progressiva" e “Chave da álgebra”. Ao olhar novamente para o Quadro 2 (acima) têm-se dados suficientes para alimentar a hipótese que eu levantei. Mas, ainda assim, cumpre realizar outras comparações entre os livros estadunidenses e os do luso-brasileiro - tarefa que não teve muito espaço ao longo desses anos de investigação porque só recentemente foi possível identificar essas referências estadunidenses de Antonio Trajano. Tais referências foram identificadas durante meu estágio de doutoramento realizado na Université de Limoges, na França, sob a orientação 
do Prof. Dr. Marc Moyon, durante o período de junho de 2015 a agosto de 2016.

Pelo que até foi analisado, julgo não ser errôneo concluir que os livros de William Guy Peck e Edward Olney bussolaram o pensamento pedagógico de Antonio Trajano. Ficou evidenciado que o nosso autor fez uma leitura didáticopedagógica dos livros escolares estadunidenses para compor seu best-seller da Aritmética do curso primário brasileiro. No aspecto didático, destacou-se a sistematização dos saberes escolares para dar a instrução aritmética aos principiantes. No nível pedagógico, evidenciaram-se as apropriações de algumas diretrizes da pedagogia norte-americana amparada no método intuitivo.

Nessas singularidades das formas de apropriação de Trajano das referências vindas dos Estados Unidos observei que uma renovação didáticopedagógica na estruturação da Aritmética escolar: a ordem do ensino sendo antecipada pela ordem do conteúdo, sob o argumento de seguir a ordem do desenvolvimento das faculdades infantis. Neste caso, a organização das operações fundamentais no livro de Antonio Trajano é um traço evidente. Dispor ilustrações e problemas antes mesmo das definições e regras era um recurso metodológico que exigia e ao mesmo tempo auxiliava os alunos a desenvolverem vários saberes-fazer (GERARD; ROEGIERS, 1993). Com este processo de ensino o saber escolar não era dado a priori, mas organizado a posteriori. Uma organização do saber a partir do desenvolvimento intelectual da criança. Esse é o modo como se estruturam os saberes escolares lidos na trilogia aritmética de Antonio Trajano, que propagava Brasil afora um ensino intuitivo da matéria.

\section{CONSIDERAÇÕES FINAIS, MAS NÃO CONCLUSIVAS...}

Para além de uma "pedagogia do olhar", de "uma pedagogia dos sentidos”, como disse Rosa Fátima de Souza (1998), apropriações brasileiras do método intuitivo fizeram emergir o imperativo da prática de saberes escolares 
úteis para a vida comum; da progressão graduada das lições e exercícios; de um ensino adaptado ao desenvolvimento intelectual da criança; enfim de uma pedagogia prático-intuitiva. Na trilogia aritmética de Antonio Trajano estes princípios pedagógicos foram unificados sob alegação de estarem de acordo com os preceitos da pedagogia moderna. Isso mostra que pedagogia altera não só os modos de ensinar, mas também a materialidade das obras didáticas e o status epistemológico dos saberes escolares. Sendo orientados pela pedagogia moderna de ensino intuitivo oriunda dos Estados Unidos, os livros escolares de aritmética com autoria de Antonio Trajano exerciam uma função mediadora nas atividades que articulavam o aluno, o professor e os saberes escolares - a tríade de interesse das pedagogias.

A análise da trilogia aritmética de Antonio Trajano revelou uma clara evidência de que o Brasil apropriou dos Estados Unidos não só um modelo pedagógico, mas também um modelo gráfico-editorial de livro escolar. As três obras aqui analisadas são testemunhas das primeiras tentativas de constituição de uma pedagogia para tornar prático e intuitivo o ensino da aritmética. A trilogia aritmética do luso-brasileiro revela uma premissa da pedagogia estadunidense, a qual foi apropriada pelo Brasil: método e aspectos gráficos deveriam estar quase indissociáveis na produção de livros escolares. As Figuras 3, 4, 5 e 6 ilustram essa premissa ao associar o método com os aspectos gráficos na finalidade de dar o ensino intuitivo da ilustração. Neste ponto de vista, considero que as aritméticas de Antonio Trajano passaram a definir um outro modelo de livro elementar de ensinar Aritmética, atrelando método e forma material - a ilustração passou a exercer papel fundamental nesta proposta de livro e de ensino elementar ${ }^{12}$.

No contexto de produção da trilogia aritmética, a ideia do mercantilismo invadia todos os ramos da sociedade, inclusive a magna questão da instrução.

\footnotetext{
${ }^{12}$ Neste contexto pedagógico, as ilustrações tinham funções metodológicas e educativas. No seu livro, Album de Gravuras para o ensino da Linguagem, Romão Puiggari fez a seguinte indicação aos professores: "As gravuras representando cenas domésticas, cenas da natureza e da vida social prestam-se para magníficos exercícios, tanto orais como escritos. Estes exercícios podem variar extraordinariamente de forma, aplicando-se a todos os anos do ensino preliminar, e moldando-se ao desenvolvimento intelectual de cada aluno" (PUIGGARI, 1898, p. I-II).
} 
Neste cenário,

traduções, imitações, plágios, tudo serve, contanto que se faça um livro para o ensino público. A tal ponto chega a ambição de fazer dinheiro por esse meio que se não pejam até de se darem como autores e tradutores de obras que nunca escreveram ou traduziram (IMPRENSA INDUSTRIAL, 1876, p. 332, grifo do original).

Mesmo sabendo desse contexto de produção de livros escolares, utilizei a expressão "trilogia aritmética de Antonio Trajano" porque na contracapa das três obras aqui analisadas está registrado que os direitos de reprodução da obra são reservados ao autor e que cada exemplar teria a sua assinatura: Antonio Trajano.

Em contrapartida, encontrei indícios que me fizeram avançar com a hipótese geral de toda essa trajetória de pesquisa: Antonio Trajano não elaborou nenhuma obra de aritmética que carregava sua autoria. Dados empíricos me permitem continuar com essa hipótese. Cito apenas uma única fonte de dados. No esboço histórico da Escola Americana de São Paulo, datado de 1932, C. T. Stewart elencou alguns pontos que foram levantados na criação e organização da escola. Entre esses pontos esteve a preparação de livros elementares que acompanhassem o método intuitivo adotado na Escola Americana. Segundo Stewart (1932, p. 8),

a série de aritmética de Trajano, tão amplamente vendida no Brasil, preparou-a Miss [Mary Parker] Dascomb, distinta professora americana que serviu muitos anos na escola, entregando-a ao seu colega, Snr. Trajano, para por ele ser editada.

Mas essa é uma hipótese que precisa ser colocada à prova em contraposição a outras duas fontes de dados ainda não consultadas: os registros de viagens de Miss Mary Parker Dascomb para os Estados Unidos, durante o período em que esteve no Brasil; e a documentação da Igreja Presbiteriana nos Estados Unidos, a fim de verificar se a Igreja adquiriu os direitos de tradução dos 
livros de William Guy Peck e Edward Olney para o português.

Enquanto não se examina tais documentos, continuou a perguntar: seria o caso de considerar Antonio Bandeira Trajano um compilador em vez de autor? Esta é uma questão que fica em aberto por ultrapassar os limites deste artigo. A escrita foi limitada pelo número de páginas estabelecido pelo periódico. Por isso, as histórias aqui contadas tiveram que ser sintetizadas. Assim sendo, este texto "é, [no fundo], apenas um convite a explorar um universo que nos é ainda bastante desconhecido" (DARNTON, 1992, p. 10). Na realidade, gostaria de utilizar a palavra universo no plural. Existem ao menos três universos a serem explorados: $1^{0}$ ) - a história da educação matemática na escola primária; $2^{\circ}$ ) a circulação de livros didáticos como portadores de "modelo" de ensino; $3^{\circ}$ ) as apropriações de Antonio Trajano dos padrões norte-americanos da matemática do curso primário. Torno a perguntar: Álgebra Elementar, Álgebra Superior e Chave de Álgebra revelam traços da leitura didático-pedagógica de Antonio Trajano dos livros escolares americanos? Essa é uma questão a ser respondida a partir de futuras investigações.

Em síntese, da introdução deste artigo a esse último parágrafo, algo merece ser destacado: um objeto de pesquisa está sempre em construção teórica. Afinal, a teorização e categorização que fiz, e que tenho feito, na análise da trilogia aritmética de Antonio Trajano não esgotou, nem esgota, a análise do objeto aqui pesquisado ${ }^{13}$. As questões que ficaram em aberto ao longo do texto evidenciam muito bem isso: o objeto (a ser) investigado é sempre uma construção teórica. ${ }^{14}$

\footnotetext{
13 Prova do não esgotamento do objeto aqui pesquisado é a continuidade da investigação acerca da Aritmética da escola primária. Refiro-me à pesquisa que atualmente desenvolvo, a saber: "A aritmética do curso primário para alfabetizar: análise histórica das dinâmicas de produção de um saber escolar, 1870-1930". Trata-se de uma investigação desenvolvida sob a supervisão da Profa. Dra. Vera Teresa Valdemarin, a partir de um estágio de pós-doutoramento realizado na Unesp de Araraquara/SP, e com o apoio financeiro da Fapesp (processo 2017/20738-5).

14 Dedico este artigo aos orientadores que me acompanharam desde a iniciação científica ao doutorado, os quais foram citados ao longo do texto, como expressão da minha singela gratidão pelos ensinamos.
} 


\section{REFERÊNCIAS}

A PROVÍNCIA DE SÃO PAULO. Seção Livre. São Paulo, p. 2, 17 de outubro de 1879 .

BITTENCOURT, Circe Maria Fernandes. Autores e editores de compêndios e livros de leitura (1810-1910). Revista Educação e Pesquisa, São Paulo/SP, v. 30, n. 3, p. 475-491, 2004.

BRAZIL. Bibliografia, Rio de Janeiro, a. 1, n. 35, p. 2, 24 de agosto de 1883.

CALKINS, Norman Allison. Primeiras Lições de Coisas: manual de ensinamento elementar para uso dos paes e professores. Rio de Janeiro: Imprensa Nacional, 1886.

CHARTIER, Roger. ¿La muerte del libro? 1. ed. Santiago, Chile: LOM Ediciones, 2010.

CHARTIER, Roger. A mão do autor e a mente do editor. Tradução George Schlesinger. 1. ed. São Paulo: Editora Unesp, 2014.

CHERVEL, André. Histoire de l'enseignement du français du XVIIe au XXe siècles. Paris: Éditions Retz, 2006.

CHERVEL, André. La culture scolaire: une approche historique. Paris: Belin, 1998.

CHOPPIN, Alain. Le manuel scolaire au collège (préambule). In: CHOPPIN, Alain; COSTA-LASCOUX, Jacqueline (org.). Le monde arabo-musulman dans les manuels scolaires français. Lyon: École Normale Supérieure de Lyon, 2011. p. 19-27.

DARNTON, Robert. Edição e sedição: o universo da literatura clandestina no século XVIII. São Paulo: Companhia das Letras, 1992.

GERARD, François-Marie; ROEGIERS, Xavier. Concevoir et évaluer des manuels scolaires. Bruxelles: De Boeck, 1993.

HILSDORF, Maria Lucia Spedo. História da Educação: leituras. São Paulo: Thompson Learning, 2007.

IMPRENSA INDUSTRIAL. A instrução pública no Rio de Janeiro. Rio de Janeiro, 10 de ago./30 set., 1876.

LEBRUN, Monique. Le manuel scolaire: d'ici et d'ailleurs, d'hier à demain. 
Québec: Presses de l’Université du Québec, 2007.

MACHADO, Maria Cristina Gomes. O decreto de Leôncio de Carvalho e os pareceres de Rui Barbosa em debate: a criação da escola para o povo no Brasil no século XX. In: STEPHANOU, Maria; BASTOS, Maria Helena Camara (org.) História e memória da educação no Brasil: século XIX. v. 2. Petrópolis: Vozes, 2005. p. 91-103.

MATOS, Alderi Souza de. Os pioneiros presbiterianos do Brasil (18591900). São Paulo: Cultura Cristã, 2004.

MESQUITA, Ilka Miglio. Memória/Identidades em relação ao ensino e formação de professores de história: diálogos com fóruns acadêmicos nacionais. 2008. Tese (Doutorado em Educação) - Universidade de Campinas (Unicamp), Campinas/SP, 2008.

MUNAKATA, Kazumi. O livro didático como mercadoria. Revista ProPosições, Campinas/SP, v. 23, n. 3 (69), p. 51-66, set./dez. 2012.

OLIVEIRA, Marcus Aldenisson. Antonio Bandeira Trajano e o método intuitivo para o ensino de Arithmetica (1879-1954). 2013. $142 \mathrm{f}$. Dissertação (Mestrado em Educação) - Universidade Tiradentes/Unit, Aracaju/SE, 2013.

OLIVEIRA, Marcus Aldenisson. Aritmética escolar e o método intuitivo: um novo saber para o curso primário (1870-1920). 2017. $280 \mathrm{f}$. Tese (Doutorado em Ciências) - Universidade Federal de São Paulo/Unifesp, Guarulhos/SP, 2017.

OLNEY, Edward. A primary arithmetic. New York: Seldon and Company, 1880 .

PECK, William Guy. Elementary arithmetic: oral and written. New York: A. S. Barnes \& Company (Davies \& Peck's), 1878.

PESTALOZZI, Johann Heinrich. Ecrits sur la méthode: tête, coeur, main. v. 1. Le-Mont-sur-Lausanne: LEP Editions, 2008.

PUIGGARI, Romão. Álbum de gravuras para o ensino da linguagem. Rio de Janeiro: Francisco Alves, 1898.

ROCHA, Heloísa Helena Pimenta; SOMOZA, Miguel. Dossiê Manuais Escolares: múltiplas facetas de um objeto cultural. Revista Pro-Posições, São Paulo, Unicamp, v. 23, n. 3, p. 21-31, 2012. 
SCHELBAUER, Analete Regina. A constituição do método de ensino intuitivo na província de São Paulo (1870-1889). 2003. Tese (Doutorado em Educação) - Faculdade de Educação, Universidade de São Paulo/USP, São Paulo, 2003.

SOËTARD, Michel. Johann Pestalozzi. Tradução Martha Aparecida Santana Marcondes, Pedro Marcondes, Ciriello Mazzetto. Recife: Fundação Joaquim Nabuco, Editora Massangana, 2010. (Coleção Educadores).

SOUZA, Rosa Fátima. Tecnologias de ordenação escolar no século XIX: currículo e o método intuitivo nas escolas primárias norte-americanas (18601880). Revista Brasileira de História da Educação, n. 9, p. 9-42, jan./jun. 2005 .

SOUZA, Rosa Fátima. Templos de civilização: a implantação da escola primária graduada no Estado de São Paulo (1890-1910). São Paulo: Ed. da Unesp, 1998.

STEWART, Charles T. Mackenzie College e Escola Americana: notas para sua história e organização. São Paulo, 1932.

TEIVE, Gladys Mary Ghizoni. Uma vez normalista, sempre normalista: cultura escolar e produção de um habitus pedagógico (Escola Normal Catarinense, 1911-1935). Florianópolis: Insular, 2008.

TRAJANO, Antonio Bandeira. Aritmética elementar ilustrada: ensino teórico e prático. 68. ed. Rio de Janeiro: Livraria Francisco Alves, 191?.

TRAJANO, Antonio Bandeira. Aritmética primária. 12. ed. Rio de Janeiro: Cia. Typ. do Brazil, 1895.

TRAJANO, Antonio Bandeira. Aritmética progressiva. 68. ed. Rio de Janeiro: Livraria Francisco Alves, 1935.

VALDEMARIN, Vera Teresa. A construção do objeto de pesquisa. In: SILVA, Marilda da; VALDEMARIN, Vera Teresa (org.). Pesquisa em educação: métodos e modos de fazer [online]. São Paulo: Editora Unesp, Cultura Acadêmica, 2010. p. 46-65.

VALDEMARIN, Vera Teresa. História dos métodos e materiais de ensino: a escola nova e seus modos de uso. São Paulo: Editora Cortez, 2010.

VALDEMARIN, Vera Teresa. Método intuitivo: os sentidos como janelas e portas que se abrem para um mundo interpretado. In: SOUZA, Rosa Fátima de; VALDEMARIN, Vera Teresa; ALMEIDA, Jane Soares de. O legado 
educacional do século XIX. Araraquara: FCL/Unesp, 1998. p. 63-106.

VALENTE, Wagner Rodrigues. Uma história da matemática escolar no

Brasil, 1730-1930. 2. ed. São Paulo: Annablume, Fapesp, 2007.

MARCUS ALDENISSON OLIVEIRA realiza um estágio de pós-doutoramento no Departamento de Ciências da Educação da Faculdade de Ciências e Letras na Universidade Estadual Paulista "Júlio de Mesquita Filho" Unesp/Araraquara. Doutor em Ciências pelo Programa de Pós-Graduação em Educação e Saúde na Infância e na Adolescência da Universidade Federal de São Paulo - Unifesp/Guarulhos. Entre 2015 e 2016, fez um estágio de doutoramento na Université de Limoges (França). Mestre em Educação e licenciado em Matemática pela Universidade Tiradentes Unit/Aracaju. Membro do Grupo de Estudos e Pesquisas sobre Cultura e Instituições Educacionais (Gepcie), desde 2018. Membro do Grupo de Pesquisa de História da Educação Matemática (Ghemat), desde 2013. Membro do Grupo de Pesquisa Histórias das Práticas Educacionais (GPHPE), desde 2009. Tem experiência na área de educação, com ênfase em história da educação matemática. Na pesquisa, interessa-se principalmente nos seguintes temas: alfabetização; métodos de ensino; ensino de matemática; livro didático de matemática.

E-mail: marcus_aldenisson@hotmail.com

(D) http://orcid.org/0000-0002-8757-0844

Recebido em: 29 de janeiro de 2018

Aprovado em: 04 de dezembro de 2018

Revista História da Educação - RHE

Associação Sul-Rio-Grandense de Pesquisadores em História da Educação - Asphe

Artigo de acesso aberto distribuído nos termos de licença Creative Commons. 